saicin closely in its stability toward boiling conc. sodium hydroxide solution and in its solubility in conc. hydrochloric acid.

The decenoic acid isolated from capsaicin, on fusion with potassium bydroxide, breaks down into acetic acid and an octoic acid with a branched chain.

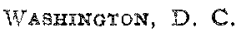

[CONTRIBUTTON FROM THE CHEMICAL LABORATORY OF THE UNIVERSITY OF ILLINOIS.]

\title{
THE USE OF OXALYL CHLORIDE AND BROMIDE FOR PRO- DUCING ACID CHLORIDES, ACID BROMIDES OR ACID ANHYDRIDES. III.
}

By Roger ADAMS ANd L. H. Ulimer.

Received Jantary 8, 1920.

It has already been pointed out in previous communications that oxalyl chloride in the presence of pyridine ${ }^{1}$ is a valuable reagent for the identification of phenols and that its action with aromatic acids ${ }^{2}$ offers a simple method for the preparation of the corresponding anhydrides. This paper contains an extension of the work with oxalyl chloride. The reactions of this substance with various aliphatic and aromatic acids as well as with the sodium salts of such acids are described. Either acid anbydricles or acid chlorides may be obtained, depending upon the conditions and proportions of materials used. Aliphatic and aromatic acid amhydrides and oxalyl chloride give the corresponding acid chlorides. The mechanism of these various reactions is explained. It has been shown also that oxalyl chloride may be used for producing certain inorganic acid chlorides from the corresponding oxides, and for causing the Beckmant rearrangement of various ketoximes. Oxalyl bromide may be employed in the same way as oxalyl chloride and yields with acids or their salts either acid anhydrides or acid bromides. Phosphorus pentabromide and organic acids or phosphorus pentabromide and the salts of organic acids yield acid bromides.

If aromatic or aliphatic acids are warmed with 2.5 moles of oxalyl chloride, these acids are converted quickly and practically quantitatively into the corresponding acid chlorides. The reaction may even be carried out in the presence of benzene as a solvent and very successful results obtained. Various types of acids were chosen for experimentation. The following give excellent yields of acid chloride: benzoic, p-bromobenzoic, o-bromobenzoic, $n$-valeric, lauric, phenylacetic, hydrocinnamic and salicylic acids. p-Hydroxybenzoic acid does not give an acid chloride but instead a complex condensation product. Certain nitro derivatives of benzoic acid react very peculiarly with oxalyl chloride; thus $m$-nitro-

1 THIS JOURNAL, 37, 2716 (I9I5).

'Ibid, 40, 424 (1918). 
benzoic, p-nitrobenzoic, 3,5-dinitrobenzoic, 2,4,6-trinitrobenzoic acids when treated as described above, all give the corresponding double anhydride of 2 moles of aromatic acid and one mole of oxalic acid. Even on reftuxing for several hours with excess of oxalyl chloride, no decomposition of these double anhydrides takes place.

Instead of using the organic acid and excess of oxalyl chloride to produce acid chlorides, it is also possible to use the sodium salts of the organic acids and oxalyl chloride. When one mole of the sodium salt of the organic acid is added gradually to $\mathrm{I}-\mathrm{I} .5$ moles of oxalyl chloride in benzene, the reaction runs smoothly with the production of sodium chloride and the organic acid chloride. In this way, benzoyl chloride and its 0 and p-chloro-, $o$ and $p$-bromo-, p-methoxy-, $m$ m and $p$-nitro-, 3,5-dinitroderivatives were formed as well as phenylacetyl chloride and cinnamyl chloride. The method is even more general than the one just described where the free organic acid is used; moreover, it is usually the method to be preferred as a smaller excess of oxalyl chloride may be used to get the maximum yields. This is due partly to the fact that less gas is evolved in the reaction so that less oxalyl chloride is lost by volatilization. The yields and the purity of the products are high. It is particularly noticeable that certain nitro derivatives of benzoic acid, which react with oxalyl chloride under the conditions described above to give double anhydrides, when allowed to react in the form of their sodium salts give exclusively acid chlorides.

Acid chlorides are also readily formed by the action of oxalyl chloride on acid anhydrides. This reaction is a smooth one and very good yields are obtained. In order to test out the scope of the reaction, the following anhydrides were converted into the corresponding acid chlorides: acetic, monochloroacetic, benzoic, $m$-nitrobenzoic, 3,5-dinitrobenzoic anhydrides. This reaction may be carried out merely by mixing oxalyl chloride with the acid anhydride alone or in the presence of benzene as a solvent and refluxing for a few hours. It is significant here that the anhydrides of the nitro derivatives of benzoic acid with oxalyl chloride readily change into the corresponding acid chlorides, whereas the doubile anhydrides of these same acids and oxalic acid are perfectly stable in the presence of oxalyl chloride.

A description of the prepatation of aromatic acid anhydrides ${ }^{1}$ by the action of one mole of oxalyl chloride upon 2 moles of organic acid in benzeve as a solvent has already been published. ${ }^{1}$ The reaction apparently is general for this class of acids and the yields are very good. Again, certain nitro derivatives of benzoic acid act somewhat peculiarly, giving double anhydrides of oxalic acid which when melted decompose to give

1 Tais JoURnal, 40, 424 (IgI8). 
the simple anhydrides. In this communication, the same procedure has been applied to the preparation of aliphatic acid anhydrides. In no case, however, are the yields so high as in the aromatic series. In most cases, certain amounts of unchanged acid and some acid chloride are obtained as by-products. The difference in yields of anhydrides with the aliphatic acids may probably be explained by the fact that the aliphatic acid anhydrides are easily converted into acid chlorides with oxalyl chloride whereas the aromatic acid anhydrides are less easily converted. The acids investigated were $n$-butyric, phenylacetic and cinnannic. The yields of acid anhydrides from aliphatic acids if no benzene is used as a solvent, are about the same as when a solvent is used.

Acid anhydrides may also be formed by the addition of one mole of oxalyl chloride to 2 or more moles of the sodium salt of the organic acids suspended in benzene. Under these conditions good yields of the aromatic acid anhydrides are obtained and in the aliphatic series; the yields are only slightly lower, the by-product of acid chloride being small. For the preparation of aliphatic acid anhydrides, the use of the sodium salts of the acids thus gives more satisfactory results than the free acids. The acids chosen for study were benzoic, $m$-nitrobenzoic, $p$-nitrobenzoic, o-chlorobenzoic, lauric, monochloroacetic, $n$-valeric and $n$-butyric. The most noticeable difference in the formation of the anhydrides from the sodium salts of the acids and from the free acids by the action of oxalyl chloride is in certain nitro derivatives of benzoic acid. These in the form of their sodium salts give simple anhydrides directly while as free acids, double anhydrides are produced.

The mechanism of the formation of these acid chlorides and acid anhycrides from oxalyl chloride and aliphatic and aromatic acids is cleared up by a consideration of the above reactions. There is no question but that the first step is the formation of a double anhydride, the second a decomposition of the double anhydride into a simple anhydride, and third, the conversion of the simple anhydride into the corresponding acid chloride as follows:

$$
\begin{gathered}
\mathrm{RCOOH}+(\mathrm{COCl})_{2} \longrightarrow(\mathrm{RCOOCO})_{2}+2 \mathrm{HCl} \\
(\mathrm{RCOOCO})_{2} \longrightarrow(\mathrm{RCO})_{2} \mathrm{O}+\mathrm{CO}_{2}+\mathrm{CO} \\
(\mathrm{RCO})_{2} \mathrm{O}+(\mathrm{COCl})_{2} \longrightarrow 2 \mathrm{RCOCl}+\mathrm{CO}_{2}+\mathrm{CO}
\end{gathered}
$$

By the isolation of the intermediate double anhydrides in many cases it has been shown that the acid anhydrides form through these compounds. It was a question, however, whether the acid chlorides as produced from the acid and excess of oxalyl chloride actually form directly or through the acid anhydrides which are secondary products from the double anhydrides. This is clarified by the fact that the acids which form stable double anhydrides do not give acid chlorides with excess of oxalyl 
chloride but instead give double anhydrides. The acid chlorides certainly have an opportunity to form directly in these reactions since the acid dissolves in the excess of oxalyl chloride and the double anhydride does not begin to separate for some time after refluxing has started. The resulis signify that in certain cases the double anhydrides are so stable that they separate out without breaking down into the simple anhydride which would in turn yield the acid chloride. If any of the simple anhydrides, and especially to be noticed are the nitrobenzoic anhydrides, are treated with oxalyl chloride there is no diffeulty in converting them practically quantitatively into the corresponding acid chlorides. The ease with which anhydrides form acid chlorides undoubtedly accoints for the presence of some acid chloride with the anhydrides, especially in the aliphatic series when 2 moles of acid are treated with one mole of oxalyl chloride.

Under ordinary conditions, it would be assumed that the mechanism of the formation of acid chlorides and acid anhydrides from the salts of the organic acids would be exactly analogous to the formation of the same compounds from the free organic acid. This probably is the case. Nevertheless, it is possible that the acid chlorides and anhydrides when formed from the sodium salts of the acids and oxalyl chlorides are not produced through the double aubydrides.

$$
\begin{gathered}
\mathrm{RCOONa}+(\mathrm{COCl})_{2} \longrightarrow \mathrm{RCOCl}+\mathrm{CO}+\mathrm{CO}_{2}+\mathrm{NaCl} \\
2 \mathrm{RCOONa}+(\mathrm{COCl})_{2} \longrightarrow(\mathrm{RCO})_{2} \mathrm{O}+\mathrm{CO}+\mathrm{CO}_{2}+2 \mathrm{NaCl}
\end{gathered}
$$

This assumption is made because of the fact that the sodiun salts of certain nitro derivatives of the aromatic acids do not yield the double anhydrides when treated with oxalyl chioride but either acid chlorides or acid anhydrides, whereas the corresponding free acids invariably yield under any conditions the double anhydrides. It is difficult to explain why the saits of the acids and free acids act differently.

Since oxalyl chloride reacts so readily with organic acids and acid anhydrides, an attempt was made to prepare certain inorganic acid chlorides by the action of oxalyl chloride on the corresponding oxide. Two were chosen for study, arsenious oxide and chromium trioxide. In both cases, refluxing with a slight excess of oxalyl chloride causes a conversion of the oxides into arsenic chloride and chromyl chloride, respectively.

$$
\begin{aligned}
& \mathrm{As}_{2} \mathrm{O}_{3}+3(\mathrm{COCl})_{2}=2 \mathrm{AsCl}_{3}+3 \mathrm{CO}_{2}+3 \mathrm{CO} \\
& \mathrm{CrO}_{3}+(\mathrm{COCl})_{2}=\mathrm{CrO}_{2} \mathrm{Cl}_{2}+\mathrm{CO}_{2}+\mathrm{CO}
\end{aligned}
$$

It is probable that this reaction could be extended to other oxides of the same sort.

Of the various reagents which may be used for the production of the Beckmann rearrangement in ketoximes, acid chlorides are by far the commonest. An attempt was made to use oxalyl chloride for this same 
purpose. The results show that it is an excellent reagent for this purpose and causes very rapid and quantitative rearrangement of benzophenone oxime, phenylanisyl ketoxime and phenyltolyl ketoxime into the corresponding acid amides.

Oxalyl bromide may be formed by the action of hydrobromic acid upon oxalyl chloride. ${ }^{1}$. This substance is extremely reactive and acts in an analogous manner to oxalyl chloride as shown by experiment. When 2 tnoles of an orgatic acid are treated in benzene with one mole of oxalyl bromide, acid anhydrides are produced; thus benzoic, $o$ - and $p$-chloro- and p-bromobenzoic acids were converted into their anhydrides. The yields are good and the constants check with those obtained by the action of oxalyl chloride on the aromatic acids. The use of oxalyl bromide in this reaction, however, is of theoretical interest only since oxalyl bromide is formed from oxalyl chloride which is just as satisfactory for the preparation of acid anhydrides.

To show that acid bromides can be produced directly from oxalyl bromide and an organic acid, $n$-butyric acid was converted to butyryl bromide. The sodium salts of acids are also converted to acid bromides by means of oxalyl bromide, thus the sodium salts of benzoic acid and its 0 -, $m$ - and $p$-chloro, 0 - and $p$-bromo, $p$-iodo-, $0-, m$ - and $p$-methyl-, $p$-methoxy-, $m$ - and p-nitro-, 3,5-dinitro derivatives as well as cinnamic and phenylacetic acids were converted to acid bromides. This particular method was extended to the large number of acids described above because it was noted in the literature that no aromatic acid bromides with the exception of benzoyl bromide had been described. These compounds could undoubtedly be produced by the action of oxalyl bromide directly on the organic acid, but since the reaction between the sodium salts of the acids and oxalyl bromide runs so smoothly and such a small excess of the oxalyl bromide is required, this method was adopted for their preparation.

Since the aromatic acid bromides have never been prepared up to the present time, it seemed desirable to determine whether the standard methods for the preparation of acid halides could be applied to these substances. Consequently the reaction between phosphorus pentabromide and certain aromatic acids and between phosphorus pentabromide and the sodium salts of certain acids was carried out. In every case acid bromides are obtained although not in such good yields or in such pure form as by the use of oxaly 1 bromide. The results indicate, nevertheless, that these general methods are applicable to the preparation of acid bromides

\section{Experimental.}

Action of Oxalyl Chloride on Organic Acids-Preparation of Acid Chlorides.-The general procedure by which acid chlorides are pro-

1 Ber. 46, I43I (I913). 
duced from acids by means of oxalyl chloride is as follows: In a round. bottom flask, the neck of which is ground to fit the bottom of a refiux condenser, is placed one mole of the organic acid and 2 to 2.5 moles of oxalyl chloride. In some cases, an evolution of gas starts immediately, indicating that the reaction is taking place; in other cases slight warming is necessary before gases are evolved. After once starting, the reaction proceeds spontaneously for 15-20 min. or sometimes even longer. After this period of time a small flame is again applied and the mixture refluxed for about 2 hours. The reaction mixture is then distilled under atmospheric pressure till the excess of oxalyl chloride is collected and then generally under diminished pressure (preferably in a flask such as is described by Noyes $^{1}$ without the separatory funnel attached, however) to obtain the acid chloride. By this method the series of acid chlorides which are given in the table below were produced:

\begin{tabular}{|c|c|c|c|c|c|c|}
\hline \multirow[b]{2}{*}{ Acid. } & \multirow[b]{2}{*}{$\begin{array}{l}\text { Wt. of } \\
\text { acid. }\end{array}$} & \multirow[b]{2}{*}{$\begin{array}{l}\text { Wt. of } \\
\text { oxalyl } \\
\text { chloride. }\end{array}$} & \multirow[b]{2}{*}{$\begin{array}{l}\text { Wt. of } \\
\text { acid } \\
\text { chloride. }\end{array}$} & \multicolumn{3}{|c|}{$\begin{array}{l}\text { B. p. or m. p. of } \\
\text { acid chlorides. }\end{array}$} \\
\hline & & & & $\begin{array}{l}\% \\
\text { Yield. }\end{array}$ & Deg. & $\begin{array}{l}\text { Mm. } \\
\text { Pressure. }\end{array}$ \\
\hline$n$-Valeric. ............ & 25 & 77 & 28 & 95 & $107-110$ & 756 \\
\hline Hydrocinnamic. . . . . . . & 35 & 60 & $3^{8}$ & 98 & II 6 & $\times 5$ \\
\hline Benzoic............... & 25 & 60 & 28 & 98 & 93 & 20 \\
\hline o-Bromobenzoic. ........ & 25 & 40 & 25 & 93 & 125 & 20 \\
\hline p-Bromobenzoic........ & 10 & I. 3 & Io & 94 & $18 I-2$ & $125\left(\mathrm{~m} \cdot \mathrm{p} \cdot 42^{\circ}\right)$ \\
\hline Lauric . . . . . . . . . . & 25 & 40 & 27 & 99 & $145-7$ & 20 \\
\hline Salicylic............. & 15 & 28 & 16.5 & 98 & $\ldots$ & $\cdots$ \\
\hline Monochloroacetic........ & 25 & 80 & 24 & 80 & $103-6$ & 750 \\
\hline Phenylacetic........... & 35 & 70 & 30 & 74 & IOO & I2 \\
\hline
\end{tabular}

It is noticeable that only in 2 cases, namely monochloroacetic acid and phenylacetic acid, do the yields drop below 90\%. Monochloroacetic acid forms an anhydride with extreme ease in the presence of almost any sort of dehydrating agent and small amounts were isolated in the above reaction. Phenylacetyl chloride is not very stable and extremely reactive, giving certain amounts of tarry material, probably condensation products between several molecules. The yields, however, in both cases, are very much better than are obtained with other acid chloride reagents with the possible exception of thionyl chloride.

The preparation of these acid chlorides can be carried out if desired in benzene as a solvent (about $50 \mathrm{cc}$. of benzene being used for a $25 \mathrm{~g}$. portion of acid); thus, both benzoic and monochloroacetic acids gave satisfactory results under these conditions. In the case of salicylic acid, because of the instability of the acid chloride, the preparation of this latter compound was not attempted except with benzene as a solvent, and after the reaction had taken place the benzene and excess of oxalyl chloride were removed by distilling off under diminished pressure at room tem-

1 THIS JOURNal, 39,27 I8 (1917). 
perature. The action of oxalyl chloride upon p-hydroxybenzoic acid was carried out but complex condensation products were obtained and no acid chloride was produced.

When excess of oxalyl chloride reacis with $m$-nitro, p-nitro-, 3,5dinitro-, and 2,4,6-trinitrobenzoic acids, the acid at first goes into solution and in the course of a few minutes a solid separates. After refluxing for 2 hours, the reaction mixture is treated directly with benzene, the olide filtered, washed with dil. sodium carbonate solution (except in the scas of the trinitrobenzoic acid), dried and washed with hot benzene. The benzene filtrates from the original reaction mixture are evaporated and a small amount of solid material is always obtained. This is unchanged acid. Of the 4 nitro compounds produced, the double anhydride of $m$-nitrobenzoic acid ${ }^{1}$ and 3,5-dinitrobenzoic acid have already been described in a previous communication and the decomposition points here agree with those previously obtained. The double anhydrides of oxalic and p-nitrobenzoic acid as well as of 2,4,6-trinitrobenzoic acid, however, are jew.

p-Nitrobenzoic Oxalic Anhydride, $\left(\mathrm{NO}_{2} \mathrm{C}_{6} \mathrm{H}_{4} \mathrm{COOCO}\right)_{20}$-This substance forms yellowish crystals, melting with decomposition at $169-170^{\circ}$ to form $p$-nitrobenzoic anhydride, white crystals from alcohol, $m, p$. $189-190^{\circ}$. The double anhydride decomposes immediately on treatment with pyridine.

Subs., $0.2159 ; 14.2 \mathrm{cc} . \mathrm{N}_{2}$ at $25^{\circ}$ and $750 \mathrm{~mm}$.

Calc. for $\mathrm{C}_{16} \mathrm{H}_{8} \mathrm{O}_{2} \mathrm{U}_{2}: \mathrm{N}, 7.2$. Found: 7.5 .

2,4,6-Trinitrobenzoic Oxalic Anhydride, $\left[\left(\mathrm{NO}_{2}\right)_{3} \mathrm{C}_{6} \mathrm{H}_{2} \mathrm{COOCO}\right]_{2}$ - - This substance forms slightly yellowish crystals which melt with decomposition at $228-230^{\circ}$ to give $\mathrm{r}, 3,5$-trinitrobenzene, m. p. $12 \mathrm{I}^{\circ}$. The properties of this double anhydride from oxalic acid and trinitrobenzoic acid are slightly different from those of the other nitrobenzoic acids; first in that when melted it gives trinitrobenzene instead of trinitrobenzoic anhydride as would be expected, and second, that it readily decomposes with sodium carbonate solution to give the sodium salt of trinitrobenzoic acid. Similar to the other nitro double anhydrides, it decomposes rapidly with pyridine.

Subs., O.I395; $18.9 \mathrm{cc} . \mathrm{N}_{2}$ at $27^{\circ}$ and $74^{8} \mathrm{~mm}$.

Calc. for $\mathrm{C}_{16} \mathrm{H}_{4} \mathrm{O}_{18} \mathrm{~N}_{6}: \mathrm{N}, 14.8$. Found: 15.2 .

Action of Oxalyl Chloride on the Sodium Salts of Organic AcidsPreparation of acid Chlorides.-The general procedure by which acid chlorides are produced from the sodium salts of acids and oxalyl chloride is as follows. A round-botton flask is used which has 2 openings; the one is a neck ground to fit a reflux condenser and the second is a side tube ( $1.5 \mathrm{~cm}$. in diameter and $2.5 \mathrm{~cm}$. long). This second side tube is cork. 1 THISS JOURNAL, 40, 424 (Ig18). 
stoppered and is used for the addition of solid sodium salt. In the flask with the reflux condenser attached is placed 1.2 to $\mathrm{I} .5$ moles of oxalyl chloride dissolved in benzene ( $20 \mathrm{cc}$. of benzene is used when about ro g. of oxalyl chloride is needed). One mole of the dry sodium salt of the acid is now added in small portions through the side arm. Upon each addition, gases are evolved. After all of the sodium salt has been added, the mixture is refuxed for 2 hours with occasional stirring to be certain that the reaction is completed. At the end of this time the sodium chloride and any traces of unchanged sodium salt of the organic acid are filtered off. The filtrate is distilled and after recovering the benzene, the acid chloride, if solid, is crystallized or if a liquid, vacurum distilled. In this way yields of acid chloride varying from $75 \%$ to over $90 \%$ are easily produced. In the experiments carried out to test the method only small amounts (Io to $20 \mathrm{~g}$.) of the sodium salts of the acid were used and consequently the loss involved in a distillation or crystallization was proportionately large. It is probable that if roo $\mathrm{g}$. lots of acid chloride should be made, the yields would be consistently over 90\%. The compounds are practically pure as obtained directly from the benzene, but in the experiments described the products were either recrystallized or once distilled. By this method, the following acid chlorides were made: cinnamyl, phenylacetyl, benzoyl; and the following substituted benzoyl chlorides: p-chloro-, o-broxno-, p-bromo-, p-methoxy-, m-nitro-, p-nitro-, and 3,5-dinitro-. The constants agreed in every case with those appearing in the literature.

Action of Oxalyl Chloride on Organic Acid Anhydrides-Preparation of Acid Chlorides.-The general procedure by which acid chlorides are produced from acid anhydrides by means of oxalyl chloride is as follows. In a round-bottom liask of the type used for the production of acid chlorides from organic acids and oxalyl chloride, is placed one mole of the organic acid anhydride and I.5 to 2.5 moles of oxalyl chloride. The mixture is gently refluxed for 2 hours. Evolution of gas takes place, as the reaction proceeds. At the end of the heating, the reaction mixture is distilled to free it from the excess of oxalyl chioride and the acid chloride which is thus obtained is purified by crystallization or distillation under atmospheric pressure or diminished pressure. By this general process, acetic, monochloroacetic, benzoic, $m$-nitro- and 3,5-dinitro-benzoic acid anhydrides were converted into the corresponding acid chlorides, and yields of $80-95 \%$ obtained.

The Action of Oxalyl Chloride on Organic Acios--Preparation of Organic Acid Anhydrides.-The general procedure by which acid anhydrides are produced from acids and oxalyl chloride is as follows. A benzene solution or suspension is made of 2 moles of aromatic acid (roo cc. of benzene for $25 \mathrm{~g}$. of organic acid) and one mole of oxalyl chloride 
is gradually run in. The mixture is refluxed for 2 hours and then the benzene distilled off. The yields of aromatic acid anhydrides' ${ }^{1}$ by this method are very good, but in the aliphatic series they seldom amount to more than $50 \%$ to $70 \%$. As by-products in these latter reactions are obtained free acid and acid chloride. The particular compounds which were studied were $n$-butyric acid ( $56 \%$ yield), phenylacetic acid ( $46 \%$ yield) and cinnamic acid $(76 \%$ yield). If these same reactions with the acids are carried out without benzene as a solvent, the yields are about the same as indicated.

The Action of Oxalyl Chloride on the Salts of Organic Acids-Preparam tion of Organic Acid Anhydrides.- The general procedure is to suspend. 2 moles of the powdered, dry sodium salt of the acid in benzene $(50 \mathrm{cc}$. of benzene for $25 \mathrm{~g}$. of sodium salt) and then to allow I. to $\mathrm{I} .2$ moles of oxalyl chloride to run in. The reaction takes place rapidly and after 2 hours refluxing, is complete. The sodium chloride is filtered off and the anhydrides are obtained by evaporation of the benzene. With some of the aromatic acids, the anhydrides are only slightly soluble in benzene and consequently must be recovered from the mixture with sodium chloride by treatment with dilute sodium carbonate. The aromatic acid anhydrides as obtained from the benzene are washed with dil. sodium carbonate solution, dried and recrystallized while the aliphatic acid anhydrides are purified by distillation with a good fractionating column. In the aromatic series, the yields are very good, amounting to $75 \%$ to $90 \%$. In the aliphatic series, however, some acid chloride is produced although in smaller amounts than when anhydrides are made from the free acids and oxalyl chloride. The sodium salts of the following acids were converted to anm hydrides as just described: benzoic, $m$ - and $p$-nitrobenzoic, 0 -chlorobenzoic, monochloroacetic ( $54 \%$ yield), $n$-butyric ( $79 \%$ yield), $n$-valeric ( $91 \%$ yield), lauric ( $80 \%$ yield). The physical constants were not different from those already given in the literature.

Action of Oxalyl Chloride on Inorganic Acids-Preparation of Inorganic Acid Chlorides. - In a flask similar to the one used in the previous experiments are placed arsenic trioxide (one mole) and excess of oxalyl chloride ( 2 moles). The reaction mixture is refluxed gently for 5 hours, during which time the oxide gradually goes into solution. The reaction mixture is then distilled, a small excess of oxalyl chloride collected first and then the arsenic trichloride, b. p. $130^{\circ}$. The yield amounts to about $95 \%$.

In the same way dry chromium trioxide (one mole) and oxalyl chloride ( 2 moles) upon refluxing for 5 hours gives an $80 \%$ yield of chromyl chloride, b. P. II $4^{\circ}-\mathrm{II} 6^{\circ}$ at $74^{8} \mathrm{~mm}$.

${ }^{1}$ Loc. cit. 
Action of Oxalyl Chloride on Certain Aromatic Ketoximes-Preparation of Substituted Acid Amides.-Benzophenone oxime, anisyl-phenyl ketoxime and phenyl-p-tolyl ketoxime are treated in the following way: One mole of the ketoxime is dissolved in a small amount of absolute ether. To the solution is added slowly $3 / 4$ of a mole of oxalyl chloride. The mixture is kept warm for to minutes, during which time acid amide separates. At the end of this period half of the ether is evaporated, the mixture cooled and the solid acid amide filtered. The yields of benzanilide, anisanilide and $p$-toluic anilide amount to over $90 \%$.

Action of Oxalyl Bromide on the Sodium Salts of Organic AcidsPreparation of Acid Bromides.-The general procedure by which acid bromides are produced from the sodium salts of the acids is exactly analogous to the method used for the preparation of acid chlorides from the sodium salts of organic acids and oxalyl chloride. The products are worked up in exactly the same way. The yields of acid bromides are in general over $90 \%$. The following table contains a list of the bromides thus prepared with their constants and chemical analyses.

Benzoyl bromide, $\mathrm{C}_{6} \mathrm{H}_{5} \mathrm{COBr}$. B. p. $218-220^{\circ}$ at $739 \mathrm{~mm}$. as compared with $218-219^{\circ}$ reported in the literature. ${ }^{x}$

o-Chlorobenzoyl bromide, $\mathrm{ClC}_{6} \mathrm{H}_{4} \mathrm{COBr}$. B. p. $143^{-1}-15^{\circ}$ at $37 \mathrm{~mm}$.

Subs., $0.2436 ; \mathrm{AgCl}+\mathrm{AgBr}, 0.3372$.

Calc. for $\mathrm{C}_{7} \mathrm{H}_{4} \mathrm{OBrCl}: \mathrm{AgCl}+\mathrm{AgBr}, 0.3392$.

m-Chlorobenzoyl bromide, $\mathrm{ClC}_{6} \mathrm{H}_{4} \mathrm{COBr}$. B. p. $\mathrm{i}_{43}-\mathrm{r} 47^{\circ}$ at $40 \mathrm{~mm}$.

Subs., $0.2580 ; \mathrm{AgCl}+\mathrm{AgBr}, 0.3860$.

Calc. for $\mathrm{C}_{7} \mathrm{H}_{4} \mathrm{OBrCl}: \mathrm{AgCl}+\mathrm{AgBr}, 0.3894$.

p-Chlorobenzoyl bromide, $\mathrm{ClC}_{6} \mathrm{H}_{4} \mathrm{COBr}$. B. p. $14 \mathrm{r}-143^{\circ}$ at $27 \mathrm{~mm}$.

Subs., $0.275 \circ ; \mathrm{AgCl}+\mathrm{AgBr}, 0.4180$.

Calc. for $\mathrm{C}_{7} \mathrm{H}_{4} \mathrm{OBrCl}: \mathrm{AgCl}+\mathrm{AgBr}, 0.4 \mathrm{r} 5 \mathrm{O}$.

o-Bromobenzoyl bromide, $\mathrm{BrC}_{6} \mathrm{H}_{4} \mathrm{COBr}$. B. p. $166-168^{\circ}$ at $\mathrm{r} 8 \mathrm{~mm}$.

Subs., $0.2420 ; \mathrm{AgBr}, 0.3464$.

Calc. for $\mathrm{C}_{7} \mathrm{H}_{4} \mathrm{OBr}_{2}: \mathrm{Br}, 60.6$. Found: 60.9.

$p$-Bromobenzoyl bromide, $\mathrm{BrC}_{6} \mathrm{H}_{4} \mathrm{COBr}$. B. p. $135^{-1} 137^{\circ}$ at $\mathrm{x} 8 \mathrm{~mm}$.

Stubs., $0.1600 ; \mathrm{AgBr}, 0.2290$.

Calc. for $\mathrm{C}_{7} \mathrm{H}_{4} \mathrm{OBr} \mathrm{r}_{2}: \mathrm{Br}, 60.6$. Found: 60.8 .

p-Iodobenzoyl bronide, $\mathrm{IC}_{6} \mathrm{H}_{4} \mathrm{COBr}$. White crystals from carbon tetrachloride ta. p. $54-55^{\circ}$. Within 2 days it turns very dark colored even though in a sealed tube.

Subs., $0.1850 ; \mathrm{AgBr}+\mathrm{AgI}, 0.2460$.

Calc. for $\mathrm{C}_{7} \mathrm{H}_{4} \mathrm{OBrI}: \mathrm{AgBr}+\mathrm{AgI}, 0.2490$.

0-Methylbenzoyl bromide, $\mathrm{CH}_{3} \mathrm{C}_{6} \mathrm{H}_{4} \mathrm{COBr}$. B. p. ${ }_{133}-\mathrm{I}_{3} 6^{\circ}$ at $37 \mathrm{~mm}$.

Subs., $0.2180 ; \mathrm{AgBr}, 0.2080$.

Calc. for $\mathrm{C}_{8} \mathrm{H}_{7} \mathrm{OBr}: \mathrm{Br}, 40.2$. Found: 40.5 .

$m$-Methylbenzoyl bromide, $\mathrm{CH}_{2} \mathrm{C}_{6} \mathrm{H}_{4} \mathrm{COBr}$. B. p. ${ }_{3} 36-137^{\circ}$ at $52 \mathrm{~mm}$.

Subs., $0.2350 ; \mathrm{AgBr}, 0.2310$.

Calc. for $\mathrm{C}_{8} \mathrm{H}_{7} \mathrm{OBr}: \mathrm{Br}, 40.2$. Found: $40 . \mathrm{I}$.

:Ber., $\mathrm{I}_{4}, 2473$ (1881). 
p-Methylbenzoyl bromide, $\mathrm{CH}_{3} \mathrm{C}_{6} \mathrm{H}_{4} \mathrm{COBr}$. B. p. $145^{-1} 49^{\circ}$ at $42 \mathrm{~mm}$.

Subs., $0.2806 ; \mathrm{AgBr}, 0.2630$.

Calc. for $\mathrm{C}_{8} \mathrm{H}_{7} \mathrm{OBr}: \mathrm{Br}, 40.2$. Found: 40.0 .

p-Methoxybenzoyl bromide, $\mathrm{CH}_{3} \mathrm{OC}_{6} \mathrm{H}_{4} \mathrm{COBr}$. B. p. $183^{-1} 86^{\circ}$ at $27 \mathrm{~mm}$.

Subs., 0.23xo; $\mathrm{AgBr}, 0.2058$.

Calc. for $\mathrm{C}_{8} \mathrm{H}_{7} \mathrm{O}_{2} \mathrm{Br}: \mathrm{Br}, 37.3$. Found: 37.6 .

$m$-Nitrobenzoyl bromide, $\mathrm{NO}_{2} \mathrm{C}_{6} \mathrm{H}_{4} \mathrm{COBr}$. B. p. $165-167^{\circ}$ at $18 \mathrm{~mm}$. The compound is a yellowish solid at room temperature and tnay be crystallized from carbon tetrachloride, m. p. $42-43^{\circ}$.

Subs,, O.I590; $\mathrm{AgBr}, 0.1315$.

Calc. for $\mathrm{C}_{7} \mathrm{H}_{4} \mathrm{O}_{3} \mathrm{NBr}$ : $\mathrm{Br}, 34.8$. Found: 35.1 .

$p$-Nitrobenzoyl bromide, $\mathrm{NO}_{2} \mathrm{C}_{6} \mathrm{H}_{4} \mathrm{COBr}$. Yellow crystals from carbon tetrachloride, m. p. $63-64^{\circ}$.

Subs., $0.2456 ; \mathrm{AgBr}, 0.2048$.

Calc, for $\mathrm{C}_{7} \mathrm{H}_{4} \mathrm{O}_{3} \mathrm{NBr}: \mathrm{Br}, 34.8$. Found: 35.0 。

3,5-Dinitrobenzoyl bromide, $\left(\mathrm{NO}_{3}\right)_{2} \mathrm{C}_{6} \mathrm{H}_{3} \mathrm{COBr}$. Yellow crystals from carbon tetrachloride, to. p. $59-60^{\circ}$.

Subs., $0.2120 ; \mathrm{AgBr}, 0.1474$.

Calc. for $\mathrm{C}_{7} \mathrm{H}_{3} \mathrm{O}_{6} \mathrm{~N}_{2} \mathrm{Br}: \mathrm{Br}, 29.3$. Found: 29.6 .

Cinnamyl bromide, $\mathrm{C}_{6} \mathrm{H}_{5} \mathrm{CH}=\mathrm{CHCOBr}$. B. p. $180-184^{\circ}$ at $40 \mathrm{~mm}$. This compound forms yellow crystals, m. p. $47-48^{\circ}$.

Subs., $0.2740 ; \mathrm{AgBr}, 0.244^{8}$.

Calc. for $\mathrm{C}_{9} \mathrm{H}_{7} \mathrm{OBr}$ : $\mathrm{Br}, 37.9$. Found: 38.0 .

Phenylacetyl bromide, $\mathrm{C}_{6} \mathrm{H}_{5} \mathrm{CH}_{2} \mathrm{COBr}$. B. p. $150-155^{\circ}$ at $50 \mathrm{~mm}$.

Subs, $0.2642 ; \mathrm{AgBr}, 0.2505$.

Calc. for $\mathrm{C}_{8} \mathrm{H}_{7} \mathrm{OBr}: \mathrm{Br}, 40.1$. Found: 40.4 .

Other Reactions with Oxalyl Bromide.-In order to determine whether oxalyl bromide might be used in place of oxalyl chloride for the production of acid anhydrides, benzoic acid, $o$ - and $p$-chloro- and $p$-bromobenzoic acids were treated in benzene in the proportion of 2 moles of acid to one mole of oxalyl bromide. The directions followed were exactly analogous to those used with oxalyl chloride and in every case very good yields of the corresponding anhydrides were produced.

In order to show that excess of oxaly 1 bromide on the organic acids will yield acid bromides in the same way that oxalyl chloride yields acid chlorides, $n$-butyric acid (one mole) was refluxed with an excess of oxalyl bromide ( 2 moles) as described under the reaction between organic acids and oxalyl chloride. After the evolution of gas stopped, the reaction mixture was refluxed for 2 hours and then distilled in the tusual way. The bromide was produced in good yields.

The Action of Phosphorus Pentabromide upon Aromatic Acids and the Salts of Aromatic Acids.-One mole of phosphorus pentabromide is suspended in benzene and one mole of organic acid is added. The mixture is refluxed for I to 2 hours, at the end of which time the reaction is complete. Upon distillation under diminished pressure, phosphorus oxybromide comes over first and then the acid bromide. In this way benzoic 
and o-chlorobenzoic acids were converted to the acid bromides. The yields amounted to about $50 \%$. The constants were the same as those already mentioned.

If the phosphorus pentabromide is suspended in benzene (50 $\mathrm{cc}$ of benzene to $25 \mathrm{~g}$. of acid) and the dry sodium salt of the acid is added gradtally, a rapid reaction takes place and after refluxing a short time is complete. The sodium bromide is filtered off and the benzene filtrate distilled, first under atmospheric pressure to remove the benzene, then under diminished pressure to remove the phosphorus oxybromide and finally the acid bromide. The yields of pure product amount to $60-75 \%$. By this method benzoic acid and its $o$ - and p-bromo-, $o$ - and $m$-methyl-, $m$-nitro, 3,5-dinitro derivatives were converted into the corresponding acid bromides.

\section{Summary.}

I. Organic acids when treated with 2 moles of oxalyl chloride alone or in benzene as a solvent are converted almost quantitatively into acid chlorides.

2. The sodium salts of organic acids when added to I.2-I.5 moles of oxalyl chloride in benzene are converted almost quantitatively into acid. chlorides.

3. Certain nitro derivatives of benzoic acid when treated as in (I) are converted into double anhydrides of oxalic acid and the aromatic acid; when treated as in (2) are converted into acid chlorides as is the case with other acids.

4. Organic acid anhydrides when treated with oxalyl chloride are converted almost quantitatively into acid chlorides.

5. Certain inorganic oxides are readily converted by oxalyl chloride into the corresponding acid chlorides.

6. Aromatic organic acids ( 2 moles) when treated in benzene solution with oxalyl chloride (one mole) are converted almost quantitatively into acid anhydrides. Aliphatic organic acids under the same treatment are converted to acid anhydrides only to the extent of $50-70 \%$, some unchanged acid and acid chloride being by-products.

7. The sodium salts of aromatic organic acids ( 2 moles) when suspended in benzene and treated with oxalyl chloride (one mole) are converted. almost quantitatively into acid anyhydrides. In the aliphatic series, the yields of acid anhydride are not so good as in the aromatic series, but much better than are obtained by the action of oxalyl chloride on the free organic acid.

8. Certain nitro derivatives of benzoic acid when treated as in (6) are converted into double anhydrides of oxalic acid and aromatic acid; when treated as in (7) are converted into acid anhydrides as is the case with other acids. 
9. The Beckmann rearrangement in ketoximes is readily produced by the action of oxalyl chloride.

Io. If organic acids or the salts of organic acids are treated with oxalyl bromide under the same conditions as in (I), organic acid bromides are produced. Several new aromatic acid bromides are described.

Ix. Organic acids are converted into their anhydrides by oxalyl bromide when treated as described in (6).

12. Organic acids or the sodium salts of organic acids are converted into acid bromides by the action of phosphorus pentabromide.

I3. The mechanism of the reaction of oxalyl chloride with crganic acids and their sodium salts is described.

URBAYA, Irto.

[CONTribution from the Division of Agriculturay, Biochemistiry, MinNesota Agricultural EXPERIMENT STATION.]

\section{A MODIFICATION OF THE APPARATUS FOR THE DETERMINA- TION OF ARGININE NITROGEN BY VAN SLYKE'S METHOD.}

By GEORGE F. HOLM.

Received January $10,1920$.

Diffictlty is sometimes encountered by beginners, and even by experienced investigators at times, in the determination of arginine nitrogen of a protein hydrolysate by Van Slyke's method. ${ }^{1}$ Even with extreme care, the use of boiling tubes, pumice, etc, cannot always prevent bumping, with the result that quite often a portion of the standard acid contained in the Folin bulb will be ejected by a sudden evolution of steam.

It has also been observed that even after cooling thoroughly upon completion of the digestion of the solution with $50 \%$ potassium hydroxide solution, a moistened strip of red litmus paper inserted into the neck of the flask will slowly turn blue (indicating ammonia). This in turn may result in a slight loss of ammonia upon the transier of the flask to a Kjeldahl distillation rack as is required in this method of procedure given by Van Slyke. We have devised a modified apparatus which eliminates these difficulties. The apparatus requires no technique in glass blowing or new material not already on hand in a chemical laboratory.

A straight piece of glass tubing $10 \mathrm{~cm}$. in length and of $3.3 \mathrm{~cm}$. diameter is fitted to a Kjeldahl trap with 2 rubber stoppers as shown in the dia. gram. Into these rubber stoppers have previously been inserted an inlet and an outlet tube for water. This serves as a condenser for vapors during the 6 hours of digestion.

To make the apparatus suitable for an ordinary Kjeldahl rack, the neck of a Kjeldatil flask is cut off to a length of about ro cm. In order to add the roo- $200 \mathrm{cc}$. of water before the final distillation of ammonia, without

D. D. Van Slyke, J. Biol. Chem., Io, I5-53 (r9y x). 